Fetal Diagnosis and Therapy

\title{
Fetal Presentation of Long QT Syndrome - Evaluation of Prenatal Risk Factors: A Systematic Review
}

\author{
Satoshi Ishikawa ${ }^{a}$ Takashi Yamada $^{a}$ Tomoyuki Kuwata ${ }^{\mathrm{b}}$ Mamoru Morikawa ${ }^{\mathrm{a}}$ \\ Takahiro Yamada $^{a}$ Shigeki Matsubara ${ }^{b}$ Hisanori Minakami ${ }^{a}$ \\ ${ }^{a}$ Hokkaido University, Sapporo, and b Jichi Medical School, Shimotsuke, Japan
}

\section{Key Words}

Long QT syndrome • Prenatal risk factors • Fetal arrhythmia

\begin{abstract}
Objective: This systematic review evaluated the existence of risk factors for the fetal manifestation of long QT syndrome (LQTS). Methods: Prenatal cardiac findings suggestive of fetal LQTS were studied using 30 English literature reports extracted from the Pubmed database (1979 to December 2011) using the search terms 'long QT syndrome', 'fetal arrhythmia' and 'congenital heart disease'. Results: LQTS accounted for $15-17 \%$ of fetal bradycardias $<110 \mathrm{bpm}$ among fetuses with a normally structured heart. Of the patients with significant prenatal findings of LQTS, $17-35 \%$ exhibited a reduced baseline fetal heart rate (FHR) of 110-120 bpm on electronic cardiotocography. Other prenatal signs were sinus or intermittent bradycardia $<110 \mathrm{bpm}$ arising from atrioventricular block, tachyarrhythmias, pleural effusion and hydrops. More than $30 \%$ of Japanese infants with LQTS born at or after the mid-1980s exhibited the above-mentioned in utero signs. Conclusions: Fetal factors including a slightly reduced baseline FHR of 110-120 bpm, bradycardia $<110$ bpm, tachyarrhythmias or clinical signs of heart failure, such as pleural effusion and hydrops, were associated with a higher frequency of LQTS. The use of these signs may help to increase the perinatal diagnosis of LQTS.
\end{abstract}

\section{KARGER}

Fax +4161306 1234

E-Mail karger@karger.ch

www.karger.com
(C) 2012 S. Karger AG, Basel

1015-3837/13/0331-0001\$38.00/0

Accessible online at:

www.karger.com/fdt

\section{Introduction}

Long QT syndrome (LQTS) is a hereditary cardiac disease characterized by a prolongation of the QT interval on basal electrocardiography and is associated with a high risk of life-threatening arrhythmias [1]. Since the identification, in 1995 and 1996, of the first 3 LQTS genes (KNNQ1, KCNH2 and SCNSA) associated with the most frequently encountered LQTS variants (LQT1, LQT2 and LQT3), 7 other genes (ANK2, KCNE1, KCNE2, KCNJ2, $C A C N A 1 c, C A V 3$ and $S C N 4 B$ ) have been confirmed or suspected of being associated with other LQTS variants (LQT4-LQT10) [1]. The disease prevalence is estimated to be close to 1 in 2,500 live births [1]. LQTS accounts for more than $10 \%$ of the causes of sudden infant death syndrome [1]. Although several reports have described the prenatal cardiac findings of single or multiple cases of LQTS [2-21], some patients with LQTS show only a slightly reduced baseline fetal heart rate (FHR) of 110$120 \mathrm{bpm}$ in utero, as shown in figure 1. Since some fetuses with LQTS die in utero or during the neonatal period and because effective measures exist that are capable of preventing life-threatening episodes, such as syncope and ventricular tachycardia [1], antenatal diagnosis or a suspicion of LQTS may be helpful for improving the outcomes of fetuses with LQTS. Accordingly, we conducted this literature review to determine which fetuses should be suspected of having LQTS.
Dr. Satoshi Ishikawa

Kita-ku, Kita 14-jo, Nishi 5-chome

Sapporo 060-8648 (Japan)

Tel. +81 117066051

E-Mail sat4@par.odn.ne.jp 


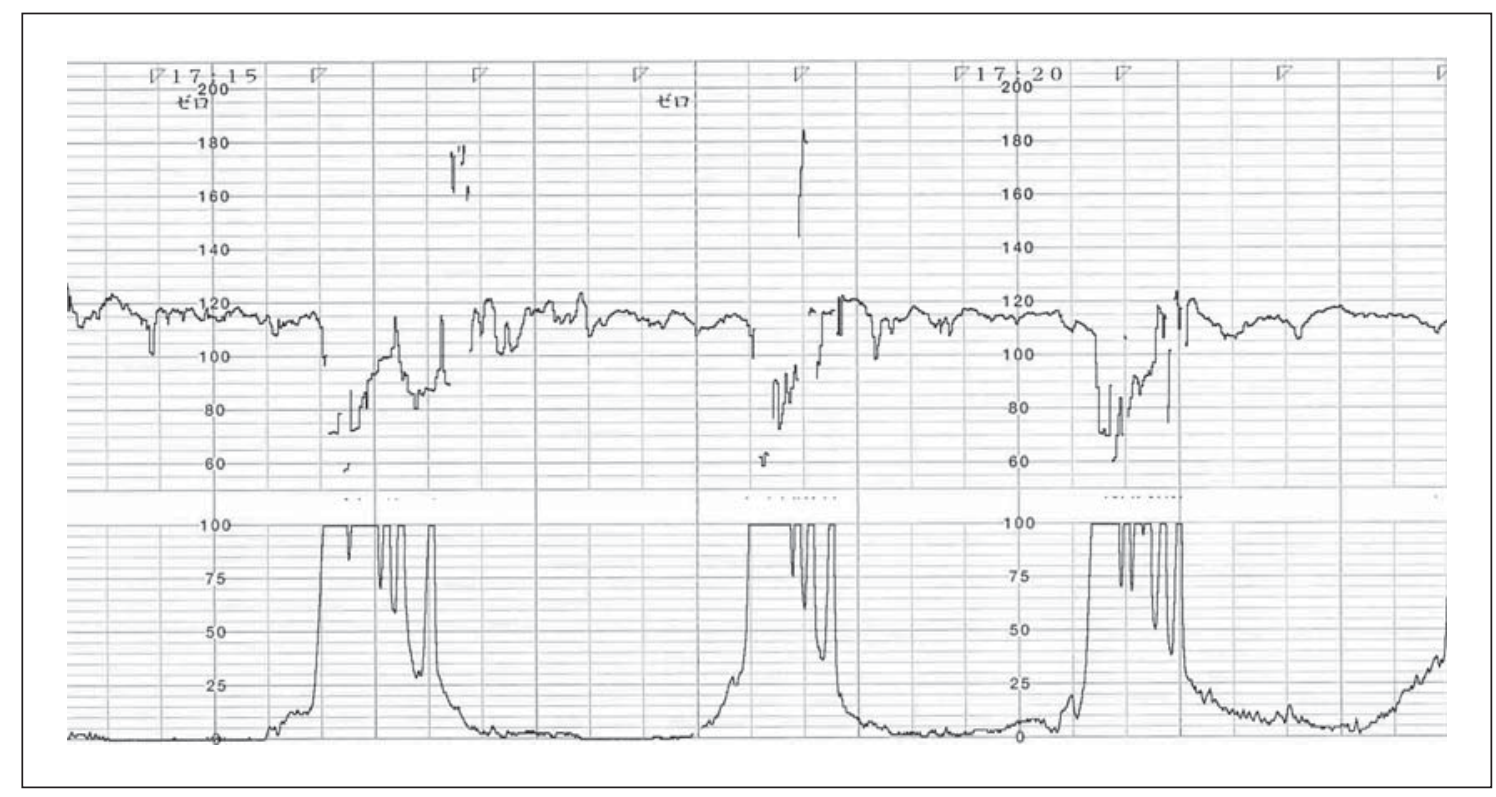

Fig. 1. Cardiotocogram obtained during labor showing a fetus with LGTS. This unpublished case was born to a mother with LQTS and showed a baseline FHR of 115 bpm during labor at 39 weeks of gestation. The infant was diagnosed as having LQTS soon after birth.

\section{Methods}

We identified a total of 30 English literature reports concerning the fetal presentation of LQTS using Pubmed (1979 to December 2011). The search terms 'long QT syndrome', 'fetal arrhythmia' and 'congenital heart disease' were used. The 30 reports were classified into three categories according to content: 20 reports [2-21] describing 21 patients with LQTS documented abnormal cardiac findings found in utero (table 1); 5 reports [23-27] described series of LQTS patients and included prenatal cardiac findings for some of the fetuses (table 2), and 5 reports [28-32] described series of fetuses, some of whom were subsequently diagnosed as having LQTS, for whom echocardiography examinations had been performed because of abnormal cardiac findings detected incidentally during antenatal care (table 3 ).

\section{Results}

Fetuses Suspected or Diagnosed as Having LQTS in utero

Table 1 shows the in utero clinical signs of fetuses with LQTS. Details of the prenatal findings for 21 fetuses were reported in 20 literature reports (table 1). The time of presentation varied from 16 to 38 weeks of gestation. Although the family history suggested the possibility of LQTS in some patients, all 21 patients exhibited disturbances of cardiac rhythm or abnormalities related to car- diac function in utero: 16 (76\%) exhibited bradycardia $\leq 110$ bpm; 4 (cases 7, 15, 16 and 21; 19\%) exhibited ventricular tachycardia or tachyarrhythmia, and 1 (case 17) exhibited pleural effusion. Eleven fetuses (52\%) were confirmed to have atrioventricular block (AVB) either pre- or postnatally. Of note, 4 fetuses (cases 6 and 9-11; 19\%) exhibited mild bradycardia ranging from 100 to $110 \mathrm{bpm}$ and a decreased baseline FHR variability on cardiotocography. Thus, fetuses with LQTS can exhibit bradycardia as a result of AVB, sinus bradycardia and tachyarrhythmias leading to a prenatal suspicion or diagnosis of LQTS. The antenatal diagnosis of a long QT interval was possible using fetal magnetocardiography $[9,11,14,20]$ or fetal electrocardiography [17].

\section{In utero Incidence of Signs of Cardiac Disease in Patients with LQTS}

As expected, not all the fetuses with LQTS were suspected of having LQTS in utero (table 2). In a report by Villain et al. [23], at least 5 out of 15 neonates (33\%) with a prolonged QT interval were documented as having bradycardia in utero, and 1 of the 5 fetuses was affected by hydrops [23] (table 2). Since the relevant information was not described in the report, the prenatal findings of the remaining 10 patients are unknown. In a report by Garson et al. [24] dealing with 287 patients with LQTS 
Table 1. Significant in utero cardiac findings in 21 fetuses reported in 20 previous reports: abnormal cardiac rhythms

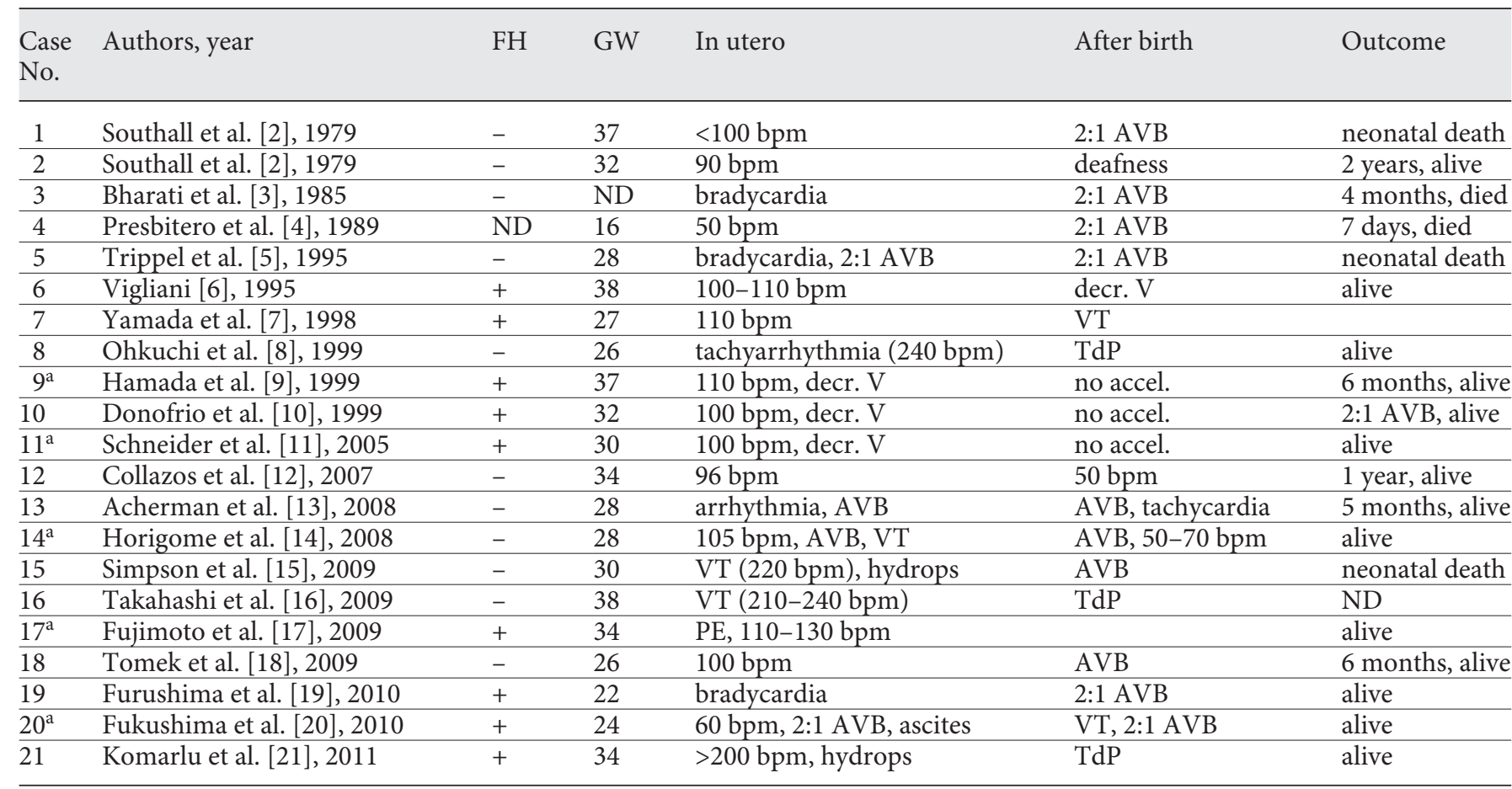

$\mathrm{FH}=$ Family history; $+=$ family history was present but does not necessarily mean that the family history was a clue to the diagnosis; AVB = atrioventricular block; decr. V = decreased baseline FHR variability on cardiotocography; $\mathrm{GW}=$ gestational week at presentation; $\mathrm{ND}=$ not described; no accel. $=$ no acceleration on cardiotocography; $\mathrm{PE}=$ pleural effusion; $\mathrm{TdP}=$ torsade de pointes; VT = ventricular tachycardia. A case reported by Green et al. [22] was not included in this table because bradycardia was noted during parturition only.

${ }^{a}$ Cases that were diagnosed as having LQTS in utero.

Table 2. Five reports describing LQTS patients with prenatal cardiac findings in some

\begin{tabular}{|c|c|c|c|}
\hline Villain et al. [23], 1992 & 15 & 5 & bradycardia in $5 ; 1$ with hydrops \\
\hline Garson et al. [24], 1993 & 287 & ND & bradycardia \\
\hline Hofbeck et al. [25], 1997 & 46 & 9 & $\begin{array}{l}\text { bradycardia }(70-100 \mathrm{bpm}), \text { AVB in } 1 \text {; bradycardia }(90-100 \mathrm{bpm}) \text { in } 1 \text {; } \\
\text { bradycardia }(100-110 \mathrm{bpm}) \text { in } 2 ; 110-120 \mathrm{bpm} \text { in } 3 \text {; VT, AVB in } 2\end{array}$ \\
\hline Horigome et al. [27] ${ }^{\mathrm{c}}, 2010$ & 58 & 18 & bradycardia in $15 ; \mathrm{AVB}$ in $8 ; \mathrm{VT} / \mathrm{TdP}$ in 7 (overlapped in some cases) \\
\hline
\end{tabular}


who were under the age of 21 years, they stated that 'the age at presentation ranged from in utero (presenting with bradycardia) to 21 years of age'. However, the number of patients with documented prenatal bradycardia was not specified in their report. A retrospective analysis of fetal echocardiography was conducted in 9 of the 46 patients with LQTS diagnosed at a single center by Hofbeck et al. [25]. Six of the $9(67 \%)$ patients exhibited abnormalities in utero: bradycardia $<110 \mathrm{bpm}$ in 4 and ventricular tachycardia and AVB in 2. Of note, the remaining 3 patients (33\%) exhibited a reduced FHR of 110-120 bpm [25]. Hofbeck et al. [25] did not mention the prenatal cardiac findings for the remaining $37 \mathrm{pa}-$ tients. Beinder et al. [26] expanded the number of patients whose cardiotocography data during gestation were available by the addition of 8 new patients to the 9 patients reported by Hofbeck et al. [25]. Six of the $17 \mathrm{fe}-$ tuses (35\%) exhibited bradycardia $<110 \mathrm{bpm}$, and 6 additional fetuses (35\%) exhibited a reduced FHR of 110 $120 \mathrm{bpm}$ [26]. Horigome et al. [27] reported 58 patients in whom LQTS was diagnosed at an age of $<1$ year. Forty-one were born between 1999 and 2008, 14 between 1989 and 1998, 1 in 1986, and 2 in 1984. Among the 18 patients with fetal presentation, clues to the diagnosis or a suspicion of LQTS included bradycardia in 15, AVB in 8 , ventricular tachycardia/torsade de pointes in 7 , and a family history of LQTS in 6 (the items overlapped in some cases). Although the definition of bradycardia was not mentioned, at least 9 fetuses (50\%) exhibited bradycardia $<110 \mathrm{bpm}$ and 3 additional fetuses (17\%) exhibited a slightly reduced FHR of 110-119 bpm [27], consistent with the results of Beinder et al. [26]. The prenatal findings of the 40 patients with clinical presentation after birth were not described [27].

Thus, based on the reports by Hofbeck et al. [25] and Horigome et al. [27], at least $20-30 \%$ of patients with LQTS exhibit initial signs suggestive of cardiac diseases in utero. Of those with prenatal findings, $17-35 \%$ exhibit a slightly reduced FHR of $110-120 \mathrm{bpm}$. However, whether the remaining $70-80 \%$ of patients with LQTS exhibited significant findings in utero remained unknown. Beinder et al. [26] suggested that approximately one third of fetuses with LQTS exhibit a normal FHR $>120 \mathrm{bpm}$, although the study population consisted of 17 patients with LQTS whose cardiotocograms during the early stage of maternal labor and/or during pregnancy were available.
Proportion of Fetuses with LQTS among Fetuses Who Underwent Echocardiography for Various Reasons

Fetal bradycardia was defined as a consistent fetal heart rate of $<100 \mathrm{bpm}$, accounting for approximately $5 \%$ of all fetal arrhythmias [33]. Approximately half of these fetuses have associated structural cardiac abnormalities, such as the corrected transposition of the great arteries, an atrioventricular septal defect or left isomerism [34, 35]. Table 3 allows us to estimate the percentage of patients with LQTS among all fetuses with abnormal cardiac findings found incidentally during routine antenatal care. Lin et al. [28] determined the underlying mechanisms of fetal bradycardia $<100 \mathrm{bpm}$ in 18 fetuses without cardiac malformations using echocardiography (table 3). Three fetuses with LQTS exhibited intermittent bradycardia and tachycardia and accounted for $17 \%$ of the 18 fetuses with a normally structured heart and bradycardia $<100 \mathrm{bpm}$ and $50 \%$ of the 6 fetuses with AVB and a normally structured heart. The bradycardia of patients with LQTS was caused by sinus bradycardia or AVB [28].

An irregular cardiac rhythm, including 'skipped beats', is a common indication for fetal echocardiography, with a frequency of at least $2 \%$ of all pregnancies [36]. Cuneo et al. [29] determined the prevalence of AVB using echocardiography in 306 fetuses with an irregular cardiac rhythm detected during routine fetal heart auscultation in the obstetrician's office or during an obstetrical ultrasound. The majority of fetuses $(97.4 \%$, i.e. $298 / 306)$ had isolated extrasystoles that were transient and benign. The remaining 8 fetuses (2.6\%) exhibited AVB in the absence of cardiac malformations. Two fetuses with LQTS exhibited sinus bradycardia and AVB, accounting for $25 \%$ of the 8 fetuses with both AVB and a normally structured heart [29].

Hsiao et al. [30] analyzed the outcomes of 123 fetuses with prenatally detected cardiac malformations and/or cardiac arrhythmias. Cardiac malformation was present in 103 fetuses, and 5 of them also had cardiac arrhythmias, accounting for $20 \%$ of the 25 fetuses with arrhythmias. Three patients with LQTS accounted for $2.4 \%$ of this population and $15 \%$ of the 20 fetuses with arrhythmias and a normally structured heart [30].

As shown by Cuneo et al. [29], most fetal arrhythmias reflect transient, isolated ectopic beats. Isolated ectopy is generally benign and self-limited [37]. However, sustained episodes of tachy- or bradyarrhythmia can lead to congestive heart failure, hydrops, or fetal or neonatal demise. Hahurij et al. [31] analyzed the causes and outcomes of 44 fetuses with prenatally detected 
Table 3. Five reports describing fetuses who underwent echocardiography because of cardiac abnormalities found incidentally during antenatal care and prenatal findings of patients with LQTS

\begin{tabular}{|c|c|c|c|c|}
\hline Authors, year & \multicolumn{2}{|l|}{ Study population } & $\begin{array}{l}\text { Patients } \\
\text { with LQTS }\end{array}$ & Specified abnormality \\
\hline Lin et al. [28], 2004 & \multicolumn{2}{|l|}{18 with fetal BC $(<100 \mathrm{bpm})^{\mathrm{a}}$ (6 with AVB) } & $3(17 \%)$ & $\mathrm{BC}, \mathrm{AVB}$ and $\mathrm{VT}$ in 3 \\
\hline Cuneo et al. [29], 2006 & \multicolumn{2}{|c|}{$\begin{array}{l}306 \text { with fetal arrhythmias } \\
\text { ( } 8 \text { with AVB, } 298 \text { with isolated extrasystole }{ }^{\mathrm{b}} \text { ) }\end{array}$} & $2(0.7 \%)$ & $\mathrm{BC}$ and $\mathrm{AVB}$ in 2 \\
\hline Hsiao et al. [30], 2007 & \multicolumn{2}{|c|}{$\begin{array}{l}123 \text { with fetal heart diseases }{ }^{\mathrm{c}} \\
\text { ( } 25 \text { with arrhythmia, } 5 \text { of the } 25 \text { had cardiac malformations) }\end{array}$} & $3(2.4 \%)$ & arrhythmia in 3 \\
\hline Eliasson et al. [32], 2011 & \multicolumn{2}{|l|}{$\begin{array}{l}65 \text { with fetal bradyarrhythmia }<110 \text { bpm } \\
\left(25 \text { with } A_{V B}{ }^{e}, 11 \text { with sinus } B C^{f}\right)\end{array}$} & $4(6.2 \%)$ & $\mathrm{AVB}$ in 1 and sinus $\mathrm{BC}$ in 3 \\
\hline \multicolumn{5}{|c|}{$\begin{array}{l}\text { In the study population, numbers of specified abnormalities } \\
\text { are indicated in parentheses. } \mathrm{BC}=\text { Bradycardia; } \mathrm{AVB}=\text { atrioven- } \\
\text { tricular block; VT = ventricular tachycardia. } \\
{ }^{\mathrm{a}} \text { Fetuses with transient bradycardia or with cardiac malforma- } \\
\text { tion were not included. } \\
{ }^{\mathrm{b}} \text { Including } 3 \text { with cardiac malformation. }\end{array}$} \\
\hline
\end{tabular}

tachy- and bradyarrhythmias after excluding sinus tachycardia, transient sinus bradycardias, premature atrial or ventricular contractions, and ventricular tachycardias. The AVB accounted for 20\% (9/44) of these arrhythmias. Two patients with LQTS accounted for $22 \%$ of the 9 fetuses with AVB and 50\% of the 4 fetuses with both AVB and a normally structured heart, after excluding 5 fetuses with both AVB and cardiac malformations [31].

Eliasson et al. [32] determined the underlying mechanisms in 65 fetuses with bradyarrhythmias $<110 \mathrm{bpm}$. Twenty-five fetuses with AVB and 11 fetuses with sinus bradycardia accounted for 38 and $17 \%$ of these fetal arrhythmias. Eight and 3 fetuses with cardiac malformations accounted for $32 \%$ of the 25 fetuses with AVB and $27 \%$ of the 11 fetuses with sinus bradycardia. Four patients with LQTS, including 1 with AVB and 3 with sinus bradycardia, accounted for $4.0 \%$ of the 25 fetuses with AVB, $27 \%$ of the 11 fetuses with sinus bradycardia, 5.9\% of the 17 fetuses with both AVB and a normally structured heart, and $38 \%$ of the 8 fetuses with both sinus bradycardia and a normally structured heart. Thus, 4 patients with LQTS accounted for $16 \%$ of the 25 fetuses with both bradycardia $<110 \mathrm{bpm}$ and a normally structured heart [32].

\section{Discussion}

The present literature review underscored the finding that fetuses with LQTS can exhibit bradycardia as a result of AVB, sinus bradycardia or tachyarrhythmias. At least $20-30 \%$ of patients with LQTS born at or after the mid1980s initially exhibited signs suggestive of cardiac diseases in utero. Among the patients with LQTS for whom documented prenatal findings were available, $17-35 \%$ of the fetuses exhibited a slightly reduced FHR of 110-120 bpm in utero, and some of these fetuses also exhibited a decreased baseline FHR variability on cardiotocograms. Among the fetuses with a normally structured heart, LQTS accounted for $15-17 \%$ of fetal bradycardias $<110$ bpm and $5.9-50 \%$ of fetal AVB.

More than two thirds of the patients with LQTS were first suspected of having LQTS after birth $[25,27]$. Whether these patients with LQTS who were initially suspected of having LQTS after birth actually exhibited significant findings in utero remains unknown, since no systematic studies focusing on the prenatal findings of patients with LQTS have been conducted to date. However, some fetuses with LQTS did indeed present with an FHR of more than $120 \mathrm{bpm}$ [26].

As suggested by Beinder et al. [26] and Horigome et al. [27], a significant number of patients with LQTS exhibited a slightly reduced FHR of $110-120 \mathrm{bpm}$ in utero, al- 
though most obstetricians presently consider a baseline FHR of $110-120 \mathrm{bpm}$ to be normal $[38,39]$. Therefore, these fetuses with a baseline FHR of 110-120 bpm may be overlooked, even though the fetuses are affected by LQTS. Because the case presented in figure 1 was born to a mother with LQTS, a postnatal investigation proved that the neonate was also affected by LQTS. Cardiotocography is routinely used to monitor fetal well-being in many countries. Persistent fetal bradycardia $<120$ bpm reportedly occurs in $<3 \%$ of all term infants [26]. Two (0.5\%) and $9(2.1 \%)$ of 430 consecutive fetuses at or after 34 weeks of gestation exhibited persistent bradycardia of 110-115 and 115-120 bpm, respectively [own unpubl. data]. Although not verified, a much higher prevalence of LQTS can be reasonably expected among fetuses with a slightly reduced FHR of $110-120 \mathrm{bpm}$ than among the general population (estimated to be one in 2,500 [1]). Suspicions of LQTS in such fetuses with a baseline FHR of 110-120 bpm irrespective of the presence or absence of a family history may increase the proportion of patients with perinatally diagnosed LQTS.
As the corrected QT interval is an independent predictor of cardiac events among patients with LQTS [40] and as LQTS accounts for more than $10 \%$ of the causes of sudden infant death syndrome [1], the early diagnosis and treatment of LQTS may help to prevent life-threatening events such as ventricular tachycardia, cardiac arrest or syncope in some patients with LQTS. In particular, attention should be paid to fetuses with a slightly reduced FHR of $110-120 \mathrm{bpm}$ as well as fetuses with bradycardia $<110$ bpm, tachyarrhythmias or clinical signs of heart failure, such as pleural effusion and hydrops. As shown in cases 6, 9, 10 and 11 in table 1, some fetuses with LQTS exhibit a reduced heart rate variability [6,9-11]. Fetal magnetocardiography is able to detect the prolongation of the QT interval $[9,11,14,20]$ as well as subtle changes in the short-term heart rate variability [41], thereby facilitating the prenatal diagnosis of LQTS $[9,11,14,20]$. Prenatal suspicions and early postnatal electrocardiograms and/ or genetic analysis may help to diagnose LQTS correctly. Such efforts may reduce the number of patients with socalled 'sudden infant death syndrome'.

\section{References}

1 Crotti L, Celano G, Dagradi F, Schwartz PJ: Congenital long QT syndrome. Orphanet J Rare Dis 2008;3:18.

-2 Southall DP, Arrowsmith WA, Oakley JR, Mcenery G, Anderson RH, Shinebourne EA: Prolonged QT interval and cardiac arrhythmias in two neonates: sudden infant death syndrome in one case. Arch Dis Child 1979; 54:776-779.

-3 Bharati S, Dreifus L, Bucheleres G, Molthan M, Covitz W, Isenberg HS, Lev M: The conduction system in patients with a prolonged QT interval. J Am Coll Cardiol 1985;6:1110 1119.

4 Presbitero P, Mangiardi L, Antolini R: Congenital long QT syndrome inducing 2:1 atrioventricular block: early detection in fetal life. Int J Cardiol 1989;24:109-112.

5 Trippel DL, Parsons MK, Gillette PC: Infants with long-QT syndrome and 2:1 atrioventricular block. Am Heart J 1995;130:11301134.

6 Vigliani M: Romano-Ward syndrome diagnosed as moderate fetal bradycardia: a case report. J Reprod Med 1995;40:725-728.

7 Yamada M, Nakazawa M, Momma K: Fetal ventricular tachycardia in long QT syndrome. Cardiol Young 1998;8:119-122

8 Ohkuchi A, Shiraishi H, Minakami H, Eguchi Y, Izumi A, Sato I: Fetus with long QT syndrome manifested by tacharrhythmia: a case report. Prenat Diagn 1999;19:990-992.
9 Hamada H, Horigome H, Asaka M, Shigemitsu S, Mitsui T, Kubo T, Kandori A, Tsukada K: Prenatal diagnosis of long QT syndrome using fetal magnetocardiography. Prenat Diagn 1999;19:677-680.

10 Donofrio MT, Gullquist SD, O'Connell NG, Redwine FO: Fetal presentation of congenital long QT syndrome. Pediatr Cardiol 1999; 20:441-444.

11 Schneider U, Haueisen J, Loeff M, Bondarenko N, Schleussner E: Prenatal diagnosis of a long QT syndrome by fetal magnetocardiography in an unshielded bedside environment. Prenat Diagn 2005;25:704-708.

12 Collazos JC, Acherman RJ, Law IH, Wilkes P, Restrepo H, Evans W: Sustained fetal bradycardia with 1:1 conduction and long QT syndrome. Prenat Diagn 2007;27:879-881.

13 Acherman RJ, Evans WN, Schwartz JK, Dombrowski M, Rollins RC, Castillo W, Haltore S, Berthody DP: Right ventricular noncompaction associated with long QT in a fetus with right ventricular hypertrophy and cardiac arrhythmias. Prenat Diagn 2008;28: 551-553.

14 Horigome $\mathrm{H}$, Iwashita $\mathrm{H}$, Yoshinaga M, Shimizu W: Magnetocardiographic demonstration of torsade de pointes in a fetus with congenital long QT syndrome. J Cardiovasc Electrophysiol 2008;19:334-335.
15 Simpson JM, Maxwell D, Rosenthal E, Gill $\mathrm{H}$ : Fetal ventricular tachycardia secondary to long QT syndrome treated with maternal intravenous magnesium: case report and review of the literature. Ultrasound Obstet Gynecol 2009;34:475-480.

16 Takahashi K, Shiraishi H, Ohkuchi A, Matsubara S, Kuwata T, Yada Y, Izumi A, Suzuki M: Irregular peak-to-peak intervals between ascending aortic flows during fetal ventricular tachycardia in long QT syndrome. Ultrasound Obstet Gynecol 2009;33:118-120.

17 Fujimoto Y, Matsumoto T, Honda N, Tojo R, Furuya M, Kasai K, Saito S, Mochimaru F, Ishikawa Y: Prenatal diagnosis of long QT syndrome by non-invasive fetal electrocardiography. J Obstet Gynaecol Res 2009;35: 555-561.

18 Tomek V, Skovranek J, Gebauer RA: Prenatal diagnosis and management of fetal long QT syndrome. Pediatr Cardiol 2009;30:194-196.

19 Furushima H, Chinushi M, Sato A, Aizawa Y, Kikuchi A, Takakuwa K, Tanaka K: Fetal atrioventricular block and postpartum augmentative QT prolongation in a patient with long-QT syndrome with KCNQ1 mutation. J Cardiovasc Electrophysiol 2010;21:11701173.

20 Fukushima A, Nakai K, Matsumoto A, Strasburger J, Sugiyama T: Prenatal diagnosis of polymorphic ventricular tachycardia using 64-channel magnetocardiography. Heart Vessels 2010;25:270-273. 
-21 Komarlu R, Beerman L, Freeman D, Arora G: Fetal and neonatal presentation of long QT syndrome. Pacing Clin Electrophysiol 2012;35:e87-e90.

-22 Green DW, Ackerman NB, Lund G, Wright D: Prolonged QT syndrome presenting as fetal bradycardia. J Matern Fetal Med 1992;1: 202-205

-23 Villain E, Levy M, Kachaner J, Garson A: Prolonged QT interval in neonates: benign, transient, or prolonged risk of sudden death. Am Heart J 1992;124:194-197.

-24 Garson A, Dick M, Fournier A, Gillette PC, Hamilton R, Kugler JD, Van Hare GF, Vetter V, Vick GW: The long QT syndrome in children: an international study of 287 patients. Circulation 1993;87:1866-1872.

-25 Hofbeck M, Ulmer H, Beinder E, Sieber E, Singer H: Prenatal findings in patients with prolonged QT interval in the neonatal period. Heart 1997;77:198-204.

-26 Beinder E, Grancay T, Menedez T, Singer H, Hofbeck M: Fetal sinus bradycardia and the long QT syndrome. Am J Obstet Gynecol 2001;185:743-747.

-27 Horigome H, Nagashima M, Sumitomo N, Yoshinaga $\mathrm{M}$, Ushinohama $\mathrm{H}$, Iwamoto $\mathrm{M}$, Shiono J, Ichihashi K, Hasegawa S, Yoshikawa T, Matsunaga T, Goto H, Waki K, Arima M, Takasugi H, Tanaka Y, Tauchi N, Ikoma $\mathrm{M}$, Inamura $\mathrm{N}$, Takahashi $\mathrm{H}$, Shimizu $\mathrm{W}$, Horie M: Clinical characteristics and genetic background of congenital long-QT syndrome diagnosed in fetal, neonatal, and infantile life: a nationwide questionnaire study in Japan. Circ Arrhythmia Electrophysiol 2010;3:10-17.
28 Lin MT, Hsieh FJ, Shyu MK, Lee CN, Wang JK, Wu MH: Postnatal outcome of fetal bradycardia without significant cardiac abnormalities. Am Heart J 2004;147:540-544.

29 Cuneo BF, Strasburger JF, Wakai RT, Ovadia $\mathrm{M}$ : Conduction system disease in fetuses evaluated for irregular cardiac rhythm. Fetal Diagn Ther 2006;21:307-313.

30 Hsiao SM, Wu MH, Jou HJ, Lee CN, Shyu MK, Shih JC, Hsieh FJ: Outcome for fetuses with prenatally detected congenital heart disease and cardiac arrhythmias in Taiwan. J Formos Med Assoc 2007;106:423-431.

31 Hahurij ND, Blom NA, Lopriore E, Aziz MI, Nagel HT, Rozendaal L, Frank PHA, Vandenbussche FPHA: Perinatal management and long-term cardiac outcome in fetal arrhythmia. Early Hum Dev 2011;87:83-87.

32 Eliasson $\mathrm{H}$, Wahren-Herlenius M, Sonesson SE: Mechanisms in fetal bradyarrhythmia: 65 cases in a single center analyzed by Doppler flow echocardiographic techniques. Ultrasound Obstet Gynecol 2011;37:172-178.

33 Wladimiroff JW, Stewart PA, Tonge HM: Fetal bradyarrhythmia: diagnosis and outcome. Prenat Diagn 1988;8:53-57.

34 Huhta JC: Uses and abuses of fetal echocardiography: a pediatric cardiologist's view. J Am Coll Cardiol 1998;31:451-458.

35 Machado MVL, Grawford DC, Anderson $\mathrm{RH}$, et al: Atrioventricular septal defect in prenatal life. Br Heart J 1988;59:352-355.
36 Southall DP, Richards J, Hardwick RA, Shinebourne EA, Gibbens GL, ThelwallJones H, de Swiet M, Johnston PG: Prospective study of fetal heart rate and rhythm patterns. Arch Dis Child 1980;55:506-511.

37 Reed Kl: Fetal arrhythmias, etiology, diagnosis, pathophysiology and treatment. Semin Perinatol 1989;13:294-304.

38 National Institute of Child Health and $\mathrm{Hu}-$ man Development Research Planning Workshop: Electronic fetal heart rate monitoring: research guidelines for interpretation. Am J Obstet Gynecol 1997;177:1385-1390.

39 Minakami H, Hiramatsu Y, Koresawa M, et al: Guidelines for obstetrical practice in Japan: Japan Society of Obstetrics and Gynecology (JSOG) and Japan Association of Obstetricians and Gynecologists (JAOG) 2011 edition. J Obstet Gynaecol Res 2011;37:11741197.

40 Priori SG, Schwartz PJ, Napolitano C, Bloise R, Ronchetti E, Grillo M, Vicentini A, Spazzolini C, Nastoli J, Bottelli G, Folli R, Cappelletti D: Risk stratification in the long-QT syndrome. N Engl J Med 2003;348:18661874

41 Schiermeier S, van Leeuwen P, Lange S, Geue D, Daumer M, Reinhard J, Grönemeyer D, Hatzmann W: Fetal heart rate variation in magnetocardiography and cardiotocography - a direct comparison of the two methods (in German). Z Geburtshilfe Neonatol 2007;211:179-184. 